Article

\title{
Hot Embossing for Whole Teflon Superhydrophobic Surfaces
}

\author{
Jie Li ${ }^{1}{ }^{(1)}$, Wentao $\mathrm{Yu}^{1}$, Deyin Zheng ${ }^{1}{ }^{(\mathbb{D})}$, Xin Zhao ${ }^{1}$, Chang-Hwan Choi ${ }^{2}{ }^{(\mathbb{D})}$ and Guangyi Sun ${ }^{1, *}$ \\ 1 Institute of Robotics and Automatic Information System \& Tianjin Key Laboratory of Intelligent Robotics, \\ Nankai University, Tianjin 300071, China; nklilijie@163.com (J.L.); ywt9107@mail.nankai.edu.cn (W.Y.); \\ zhengdy@mail.nankai.edu.cn (D.Z.); zhaoxin@nankai.edu.cn (X.Z.) \\ 2 Department of Mechanical Engineering, Stevens Institute of Technology, Hoboken, NJ 07030, USA; \\ cchoi@stevens.edu \\ * Correspondence: guangyi@nankai.edu.cn; Tel.: +86-22-2350-5706
}

Received: 30 May 2018; Accepted: 16 June 2018; Published: 22 June 2018

\begin{abstract}
In this paper, we report a simple fabrication process of whole Teflon superhydrophobic surfaces, featuring high-aspect-ratio $(>20)$ nanowire structures, using a hot embossing process. An anodic aluminum oxide (AAO) membrane is used as the embossing mold for the fabrication of high-aspect-ratio nanowires directly on a Teflon substrate. First, high-aspect-ratio nanowire structures of Teflon are formed by pressing a fluorinated ethylene propylene (FEP) sheet onto a heated AAO membrane at $340{ }^{\circ} \mathrm{C}$, which is above the melting point of FEP. Experimental results show that the heating time and aspect ratios of nanopores in the AAO mold are critical to the fidelity of the hot embossed nanowire structures. It has also been found that during the de-molding step, a large adhesive force between the AAO mold and the molded FEP greatly prolongs the length of nanowires. Contact angle measurements indicate that Teflon nanowires make the surface superhydrophobic. The reliability and robustness of superhydrophobicity is verified by a long-term $(\sim 6.5 \mathrm{~h})$ underwater turbulent channel flow test. After the first step of hot-embossing the Teflon nanowires, microstructures are further superimposed by repeating the hot embossing process, but this time with microstructured silicon substrates as micromolds and at a temperature lower than the melting temperature of the FEP. The results indicate that the hot embossing process is also an effective way to fabricate hierarchical micro/nanostructures of whole Teflon, which can be useful for applications of Teflon material, such as superhydrophobic surfaces.
\end{abstract}

Keywords: Teflon; hot embossing; nanowire; superhydrophobic surface

\section{Introduction}

Superhydrophobic surfaces have attracted great interest for decades because of their unique water-repelling characteristics, such as high contact angles $\left(>150^{\circ}\right)$ and low contact angle hysteresis $\left(<10^{\circ}\right)$ for a water droplet [1,2], and their applications, including self-cleaning, antifouling, anti-icing, and hydrodynamics drag reduction [3-6]. Basically, superhydrophobicity is regulated by both surface chemical composition and surface roughness [7]. For example, the surface of a lotus leaf is made of micro/nanostructures with a hydrophobic wax-like material. The micro/nano-structured hydrophobic surface can retain air among the structures and support a water droplet by only a fraction of their tips. Such a partial contact between the solid surface and a liquid droplet allows the droplet to have low adhesion and pinning so that a droplet can easily roll off the surface, which typically accompanies the removal of dust on the surface, the main mechanism allowing the lotus leaf to maintain its self-cleanness [8]. For artificial superhydrophobic surfaces, the most widely used strategy is to roughen a substrate surface with micro or nanofabrication processes, followed by a separate surface treatment 
or modification step, to lower the surface energy [9-15]. However, in practical applications, this kind of approach requires two different steps-physical surface texturing and chemical surface coating —and has serious drawbacks, such as peeling-off and degradation of the chemical coating. To overcome such an issue, it is desirable to roughen or texture a surface that is intrinsically hydrophobic so that the extra chemical treatment or coating is not necessary. This enhances the robustness and reliability of the superhydrophobicity of the surface.

Recently, thermoplastic polymers, such as low-surface-energy materials, have aroused wide concern in recent years [16-22] because of their strong hydrophobicity, electrical insulating, formable and flexible mechanical properties, and chemical inertness to acids and alkali metals [23-26]. Therefore, many researchers have explored the fabrication of superhydrophobic surfaces, based on such a kind of thermoplastic polymer, with various techniques, such as photolithography processes [27-30], etching techniques [31,32], and polymer imprinting [33-35]. These techniques have been successful in demonstrating the fabrication of superhydrophobic surfaces, although the processes are relatively complicated and costly. Photolithography processes need exposure tools with sophisticated fabrication steps and have the limitation of a minimum feature size (not feasible for fabricating nanometer-scale structures) [27-30]. Techniques based on the plasma etching also require expensive machines as well as complex preparation and fabrication steps [31,32]. More importantly, it is increasingly difficult to precisely control the fabricated structures on a nanometer scale. Therefore, there is still demand for the development of simple and economical fabrication methods that are capable of precisely controlling the dimensions and shapes of nanostructures. Alternatively, a hot embossing process has been regarded as a more cost-efficient and scalable technique for the fabrication of polymer structures, both on micrometer and nanometer scales, with high fidelity, good resolution, and less uncertainty [21,36-40]. However, most hot embossing processes were implemented in a vacuum condition with extra devices and, more importantly, were mostly developed for polymers with relatively low melting temperatures (less than $200{ }^{\circ} \mathrm{C}$ ). A hot embossing process based on a roll-to-roll mode [41] is fast and scalable, allowing for mass production. However, it remains challenging to produce high-aspect-ratio nanometer-scale structures with a good fidelity and structural hierarchy in the roll-to-roll mode. To be able to design and fabricate high-aspect-ratio nanostructures with good regulation of structural hierarchy is of great significance for many applications, such as superhydrophobic surfaces. For the hydrophobic polymers with higher melting temperatures, such as fluorinated ethylene propylene (FEP), very few attempts have been made to fabricate nanometer-scale structures using a hot embossing process; most attempts have focused on making micrometer-scale patterns [42-44].

In this work, we explore a hot embossing process to fabricate high-aspect-ratio nanowire structures of whole Teflon. The hot embossing process is directly applied to a Teflon FEP sheet using a nanoporous anodic aluminum oxide (AAO) membrane. More specifically, we investigate the effect of the heating time and aspect ratio of the nanopore structures of the AAO mold on the fidelity of the hot-embossed nanowire structures. We further examine the superhydrophobicity of the nanostructured whole Teflon surface. The robustness and durability of the superhydrophobicity of the nanostructured whole Teflon surface is also tested in an underwater turbulent channel flow. The fabrication of hierarchical nanostructures is also demonstrated by employing two-step hot embossing processes using the nanoporous AAO membrane followed by microstructured silicon modes.

\section{Fabrication Scheme}

The schematic of the proposed two-step hot-embossing processes to fabricate hierarchical structures of Teflon is shown in Figure 1. The formation of nanowire structures using an AAO mold is shown in Figure 1a. The AAO mold is coated with Teflon AF1600 as a lubrication layer to facilitate the de-molding of a molded Teflon FEP from the AAO mold after hot embossing. Without the Teflon (AF1600) coating, both the Teflon FEP and AAO mold are prone to deformation and distortion during the de-molding step because of the large adhesion and friction between them. After lubrication treatment, the AAO mold is heated to a temperature, greater than the melting temperature of embossed 
Teflon, to let the Teflon FEP sheet completely melt and reflow into the nanopores in the AAO mold. During a hot embossing process, a Teflon FEP sheet is placed on top of the heated AAO mold and covered with a glass slide. Pressure is then applied onto the cover glass to help fill the nanopores with Teflon FEP. Stacked layers, including the AAO mold and the Teflon FEP sheet attached to the glass slide, are then transferred to a stainless-steel desk at room temperature to cool down. Further, the fabrication of hierarchical micro/nanostructures using a microstructured silicon mold is shown in Figure 1b. The hot embossing process is simply repeated with the microstructured silicon mold directly on the nanostructured Teflon FEP substrate.

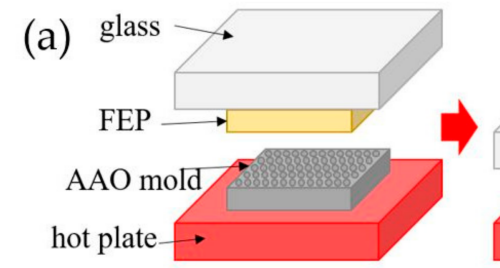

(b)

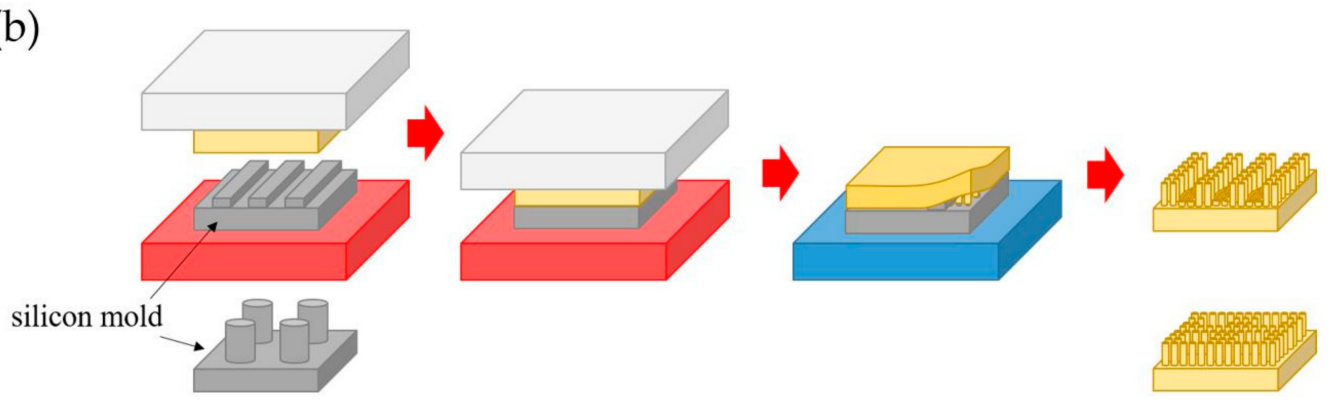

Figure 1. Schematics of hierarchical hot embossing processes. (a) Fabrication of nanowire structures with an AAO mold; (b) Fabrication of microstructures with a silicon mold.

\section{Methods and Materials}

\subsection{Preparation of $A A O$ Molds}

Nanoporous AAO molds are made based on the anodization of aluminum (Al) in electrolytic solutions. Anodization is a scalable fabrication method to form self-ordered nanometer-scale pore structures of an oxide layer of metallic substrates, such as aluminum. Depending on the anodizing solution, the acidity of the electrolyte, anodizing voltage and temperature, the thickness of the oxide layer and the dimension of the nanometer-scale pores can be conveniently modulated [45-47]. In our study, AAO molds $(18 \mathrm{~mm} \times 18 \mathrm{~mm} \times 0.5 \mathrm{~mm})$ with different diameters and spacing were purchased from Lesson Nano Technology Co., Ltd. (Shenzhen, China). Various types of AAO molds with different dimensions were prepared, as summarized in Table 1, to examine the effect of the aspect ratio on the fidelity of the nanowire formation via hot embossing. The SEM image of one of the AAO molds (V shape, pore diameter of $400 \mathrm{~nm}$ upper and $100 \mathrm{~nm}$ bottom, pore depth of $500 \mathrm{~nm}$ ) used in this study is shown in Figure 2a. All AAO molds were ultrasonically cleaned in acetone and then rinsed with deionized water before hot embossing. To facilitate the de-molding of a Teflon FEP film from the AAO mold without destroying the nanopores [48], the AAO molds were coated with $0.05 \%$ Teflon solution, which was prepared by mixing AF1600 powders (DuPont Company, Wilmington, DE, USA) in an FC-40 solution (Sigma-Aldrich, St. Louis, MO, USA). The Teflon solution was applied to the AAO molds using a dip coating method at room temperature in a vacuum condition to ensure that the nanopores were completely filled with the Teflon solution. Next, the Teflon-coated AAO molds were baked at $170{ }^{\circ} \mathrm{C}$ for $5 \mathrm{~min}$ to evaporate the FC-40 solvent, and then at $340{ }^{\circ} \mathrm{C}$ for $30 \mathrm{~min}$ to reflow the Teflon coating, achieving a uniform coverage on the nanopore inner surface. The thickness of the 
Teflon coating is around $50 \mathrm{~nm}$, which makes the actual pore size of the AAO mold a bit smaller than its original size, as shown in Figure $2 b$.

Table 1. Dimensions of the AAO molds employed in this study.

\begin{tabular}{cccc}
\hline Name & Pore Diameter $(\mathbf{n m})$ & Interpore Distance $(\mathbf{n m})$ & Pore Depth $(\mathbf{n m})$ \\
\hline VM-01 & $400 \pm 20$ (upper part) & $530 \pm 20$ & $500 \pm 20$ \\
LJ-04 & $100 \pm 20$ (bottom part) & $530 \pm 20$ & $2000 \pm 20$ \\
LJ-05 & $150 \pm 20$ & $530 \pm 20$ & $2000 \pm 20$ \\
SP-01 & $200 \pm 20$ & $450 \pm 20$ & $2500 \pm 20$ \\
SP-03 & $250 \pm 20$ & $450 \pm 20$ & $450 \pm 20$ \\
\hline
\end{tabular}

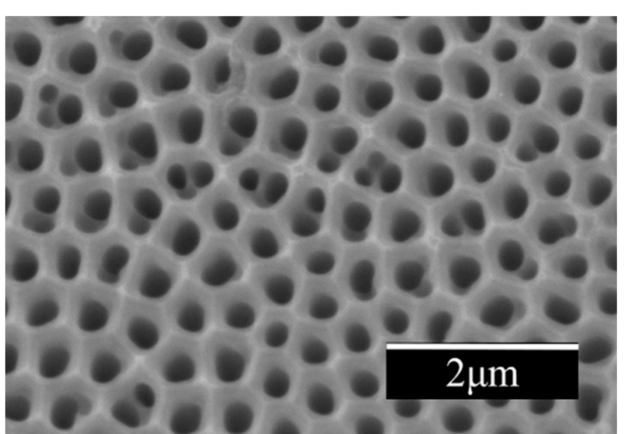

(a)

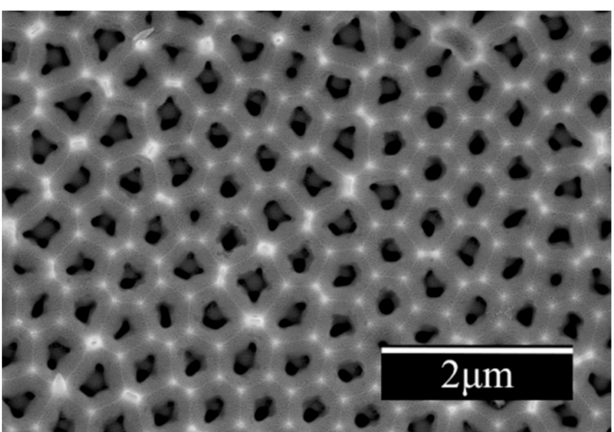

(b)

Figure 2. Scanning electron microscope (SEM) images of an AAO mold (VM-01). (a) Before Teflon coating; (b) After Teflon coating.

\subsection{Fabrication of Micromachined Silicon Molds}

A single-side polished $500 \pm 5 \mathrm{~m}$-thick silicon wafer (4 inch, $p$-type $<100>,<0.01 \Omega \cdot \mathrm{cm}$ ) was used as a silicon substrate. A Photolithography process using mask aligner (MA6, Karl Suss, Schleissheimer, Germany) and a deep reactive ion etching (DRIE) process with an inductively coupled plasma etching machine (Surface Technologies Systems USA Inc., Redwood, CA, USA) were used to form two different types of microstructures: A parallel array of grates and a square array of circular pillars. With respect to the grates, the ridge width varied from 10 to $20 \mu \mathrm{m}$, while the center-to-center pitch was maintained at $50 \mu \mathrm{m}$. With respect to the pillars, the diameter varied from 3 to $20 \mu \mathrm{m}$, while the center-to-center pitch was maintained at $50 \mu \mathrm{m}$. The DRIE etching time was regulated, resulting in an etch depth of $\sim 40 \mu \mathrm{m}$ for both patterns. The etched silicon wafer was then ultrasonically cleaned in acetone and isopropyl alcohol solutions for $5 \mathrm{~min}$, followed by ultrasonic cleaning with deionized water for $5 \mathrm{~min}$. The SEM images of the microstructured silicon molds are shown in Figure 3.

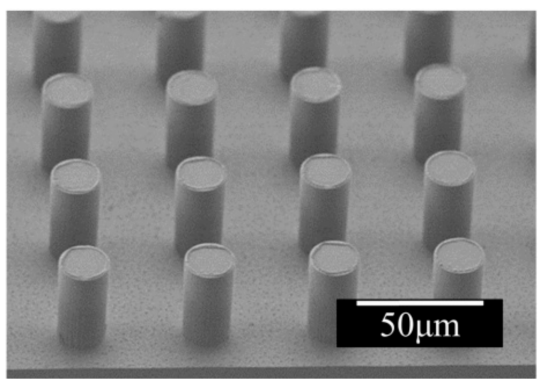

(a)

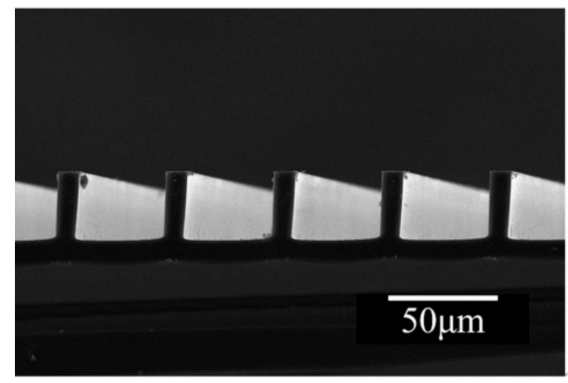

(b)

Figure 3. SEM images of microstructured silicon molds. (a) Micropillars; (b) Microgrates. 


\subsection{Hot Embossing}

For the hot embossing of high-aspect-ratio nanowire structures using the nanoporous AAO mold (Figure 1a), a Teflon FEP sheet (DuPont Company, Wilmington, DE, USA) with a thickness of $\sim 0.5 \mathrm{~mm}$ was used as a substrate. We cut the Teflon FEP sheet into pieces of $2 \mathrm{~cm} \times 2 \mathrm{~cm}$ using a stainless knife. Then, we put the Teflon FEP piece on the heated AAO molds at $340{ }^{\circ} \mathrm{C}$. At the same time, a rigid glass slide was put and pressed down on the top of the Teflon FEP piece in order to apply uniform pressure over the surface. During the hot embossing process, additional pressure was applied with wafer tweezers on the top of the glass cover to help the melted Teflon FEP to fill the nanopores more effectively. After embossing, the stack of Teflon FEP sheets on the glass slide and the AAO mold was transferred to a stainless-steel desk at room temperature for cooling. Then, the glass slide was removed from the Teflon surface and the Teflon FEP sheet was detached from the AAO mold by manually peeling off the FEP sheet from one edge. In order to produce nanowire structures with good fidelity after demolding, the AAO mold was recoated with Teflon AF1600 after around 10 cycles of the molding/demolding processes. Otherwise, the demolding process would not have been effective, causing non-uniform coverage of the nanostructures (e.g., broken or missing nanowires in some regions), which would most likely be due to the peel-off of the Teflon coating from the AAO nanopore walls. For the hierarchical fabrication of microstructures onto the nanostructured Teflon sheet, we repeated the hot embossing process using a microstructured silicon mold. Similar to the first-step (the hot embossing process employing AAO molds), we first lubricated the silicon mold with Teflon AF1600 using the same method. Then, we placed the nanostructured Teflon FEP sheet onto the microstructured silicon mold, with the glass slide on top of the Teflon sheet. Then, the whole stack was transferred to a preheated hotplate and uniformly heated at $100{ }^{\circ} \mathrm{C}$ for $80 \mathrm{~s}$, with uniform pressure applied by tweezers on top. It should be noted that the heating temperature in this step is below the melting point of Teflon FEP. Therefore, the microstructures are not formed by melting but formed through physically compressing the nanowires down to the substrate. In this case, the pressure applied by the tweezers helped to avoid any movement between the Teflon FEP sheet and the silicon mold. After embossing, the whole stack was quickly transferred to a stainless-steel desk at room temperature to cool down. After cooling, the glass slide was removed from the Teflon surface, and the Teflon sheet was de-molded from the silicon mold by manually peeling the FEP sheet from one edge.

\subsection{Contact Angle Measurement}

To examine the enhanced hydrophobicity of the Teflon FEP surface by nanowire structures, apparent contact angles of water droplets on the surface were measured with a goniometer system (Beijing Zhongjingkeyi Technology Co., Ltd., Beijing, China and Zolix Instruments Co., Ltd., Beijing, China) in a room condition. A water droplet $(1.4 \mu \mathrm{L})$ with a diameter of $1.5 \mathrm{~mm}$ was dispensed on top of the surface by a needle to measure the initial quasi-static contact angle. Then, the advancing and receding contact angles of a water droplet with an increased size ( $3.2 \mathrm{~mm}$ in a diameter)—to preclude the effect of a needle $(0.24 \mathrm{~mm}$ in a diameter) on the profile and contact angles of a droplet-were measured [49]. The advancing contact angle $\left(\theta_{\mathrm{a}}\right)$ and the receding contact angle $\left(\theta_{\mathrm{r}}\right)$ were measured as the droplet volume through the needle gradually increased and decreased, respectively, taken as the apparent contact angle when the evident movement of the contact line at the droplet base was observed. Then, the contact angle hysteresis $\left(\theta_{\mathrm{h}}\right)$ was evaluated as the difference between the advancing contact angle and receding contact angle (i.e., $\theta_{\mathrm{h}}=\theta_{\mathrm{a}}-\theta_{\mathrm{r}}$ ). The contact angle measurement was performed at six different locations on the surface and the average value was used for the evaluation.

\subsection{Measurement of Underwater Superhydrophobicity in Turbulent Flow}

According to the Cassie-Baxter wetting theory [50], the high-aspect-ratio nanowire structures make the Teflon FEP surface superhydrophobic by entraining the air between the water and surface. The air-retained superhydrophobic surface is of great significance for many applications [51,52], such as 
hydrodynamic drag reduction [53-55], anti-biofouling [56], anti-corrosion [57], and anti/de-icing [58]. Thus, we also tested the retentivity of the entrained nanowired Teflon FEP surface under a turbulent flow of water using a water tunnel. The customized water tunnel used for the test is shown in Figure 4. The Teflon surface is attached to the test section wall with double-sided tape, which is located in the middle of the channel $(5 \mathrm{~cm} \times 5 \mathrm{~cm} \times 50 \mathrm{~cm})$. The retentivity of the air on the surface under a turbulent flow of water was examined by monitoring the reflection of light from the surface. The water flow velocity is $\sim 1.2 \mathrm{~m} / \mathrm{s}$, the Reynolds number is $\sim 6.7 \times 10^{4}$, which is calculated by $\operatorname{Re}=u \cdot L / v$, where $u$ is the velocity of the fluid with respect to the object $(\mathrm{m} / \mathrm{s}), L$ is a characteristic linear dimension $(\mathrm{m})$, and $v$ is the kinematic viscosity of the fluid $\left(\mathrm{m}^{2} / \mathrm{s}\right)$ [59]. The water used in the water tunnel is considered fully saturated with air, as it has been several months since the initial injection. If the air is well retained on the surface, a silvery mirror-like color is shown on the surface, which is due to the total internal reflection of light from the air layer sheathing between the surface and water [60].

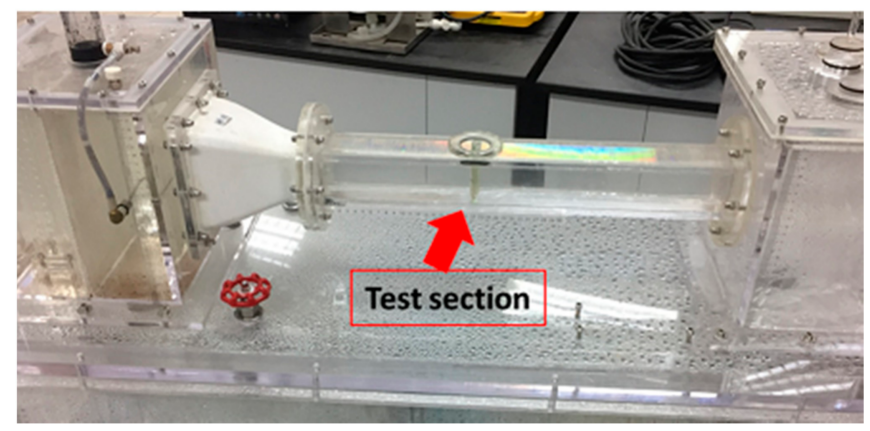

Figure 4. Water tunnel used for the underwater superhydrophobicity test in turbulent flow. Test section for the sample is located in the middle of the channel.

\section{Results and Discussion}

\subsection{Effects of Aspect Ratio}

The aspect ratio of the AAO mold also has a significant influence on the fidelity of the replicated nanowires. This is because the mechanical properties of the nanowires, such as strength and stiffness, are directly related to their aspect ratio. Apparently, the nanowire structures with a lower aspect ratio are stiffer than those with a higher aspect ratio, as shown in Figure 5. The nanowire structures shown in Figure 5a,b are made using the AAO molds of VM-01 and SP-03, respectively. Both molds have nanopores whose aspect ratios (depth to diameter) are less than 4:1. The result shows that the fidelity of the replicated nanowires is good (uniform coverage of the nanowires over the surface with no significant damage or aggregation of the nanowires) when using an AAO mold with an aspect ratio less than 10:1. When the aspect ratio of the AAO mold is around 10:1 (LJ-05 mold), significant bending and aggregation of the nanowires can be observed, as shown in Figure 5c. When using an AAO mold with an aspect ratio greater than 10:1 (LJ-04 mold), the bending and clustering of the nanowire structures become more serious, as shown in Figure $5 \mathrm{~d}$. While the aspect ratio of AAO mold affects the aspect ratio of the replicated nanowires, the results also show that the aspect ratios of the replicated nanowires are usually much greater than those of the AAO molds themselves. As illustrated in Figure $5 c, d$, the aspect ratios of the replicated nanowires are much greater than $30: 1$, although the aspect ratios of the nanopores in the AAO molds (LJ-05 and LJ-04, respectively) are less than 20:1. This is attributed to the adhesive force between the Teflon FEP and the AAO mold as well as the elasticity of the Teflon FEP. During the de-molding process, the adhesive force retards the dislodging of the Teflon FEP from the nanopores so that the elasticity of the Teflon FEP allows for the elongation of the nanowires during the withdrawal of the polymer from the AAO mold. 


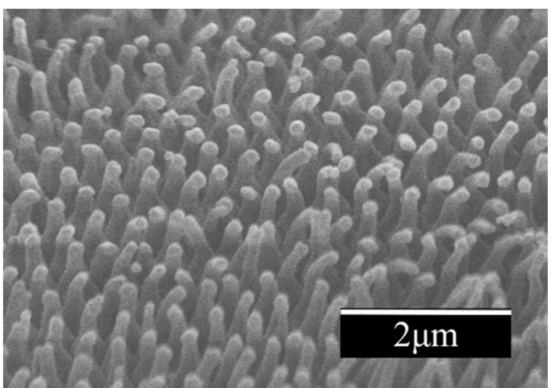

(a)

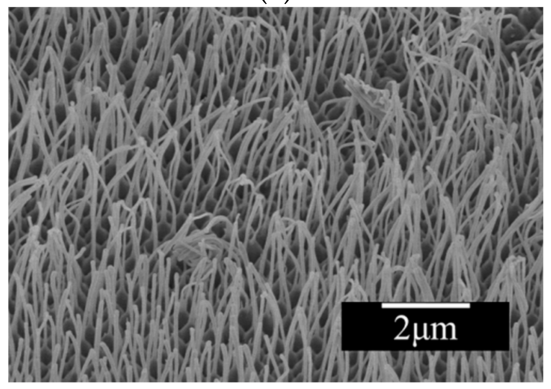

(c)

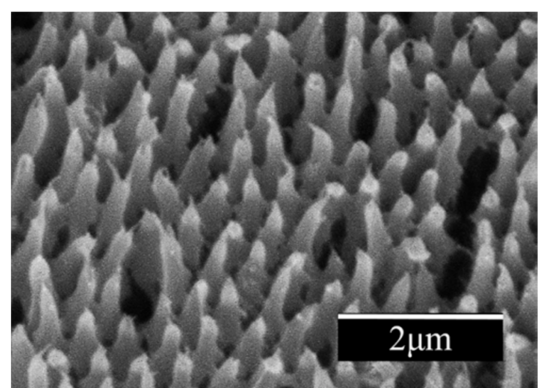

(b)

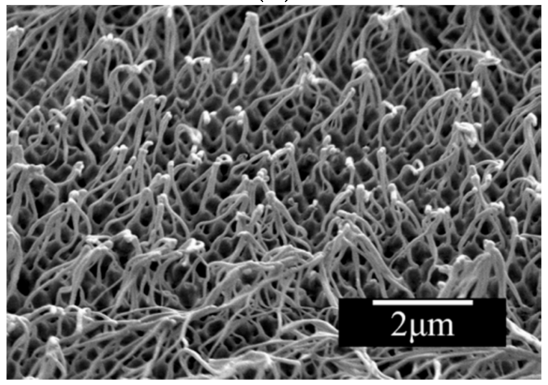

(d)

Figure 5. SEM images of nanowire structures replicated using the AAO molds with different aspect ratios, including (a) VM-01, (b) SP-03, (c) LJ-05, and (d) LJ-04 molds, respectively (see Table 1 for the details of the dimensions of the different AAO molds).

\subsection{Effects of Heating Time}

Heating time also affected the aspect ratio of the replicated nanowire structures. For example, the relationship between the dimensions of nanowires and the heating time, when the AAO mold of SP-03 (used for the nanowire structures shown in Figure $5 \mathrm{~b}$ ) was employed in the hot embossing at $340{ }^{\circ} \mathrm{C}$, is shown in Figure 6. The result (Figure 6a) shows that the length of the nanowire increases with the heating time, while the diameter slightly decreases with the heating time. Thus, the aspect ratio of nanowire structures increases significantly with the heating time, specifically, in this study, in $16 \mathrm{~min}$ (Figure 6b). The results indicate that the increase in the heating time allows the melted Teflon FEP to fill the nanopores of AAO mold more faithfully and to increase the effective contact area and hence the adhesion force between the Teflon FEP and the nanopore walls of the AAO mold. Therefore, during the demolding step, the nanowire structures of the Teflon FEP should be elongated as the heating time increases.
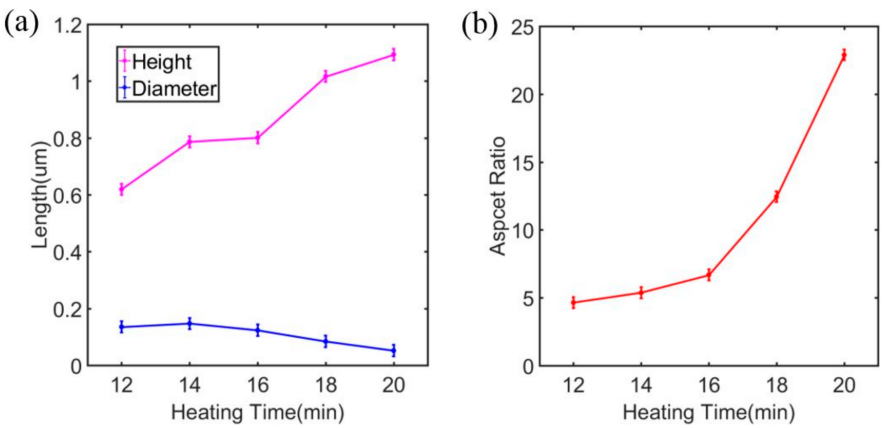

Figure 6. Characterizations of the dimensions of Teflon FEP nanowires with respect to heating time in hot embossing. (a) The average values of height and diameter of nanowire structures measured at six different points on each sample; (b) The aspect ratios of the nanowires estimated by the average values of the height and diameter over the heating time. 


\subsection{Apparent Contact Angles of Nanowired Teflon FEP Surfaces}

To examine the uniformity of the replicated nanowire structures of Teflon FEP and the reproducibility of the hot embossing process, as well as the effects of nanowire structures on the hydrophobicity of the surface, contact angles of a sessile droplet of water on the nanowired FEP surfaces have been measured. For example, the apparent quasi-static contact angles of six different Teflon FEP surfaces, made with the same AAO mold of SP-01, are shown in Figure 7a. Additionally, the contact angle hysteresis of six different Teflon FEP surfaces, made with the same AAO mold of SP-01, is shown in Figure 7b. The quasi-static contact angle and the contact angle hysteresis of a smooth (non-patterned) Teflon FEP film were $92^{\circ} \pm 3^{\circ}$ and $25^{\circ} \pm 3^{\circ}$, respectively. The results show that the high-aspect-ratio nanowire structures of whole Teflon, fabricated by the hot embossing process, increases the hydrophobicity of the Teflon significantly, allowing superhydrophobicity (a contact angle higher than $150^{\circ}$, with a contact angle hysteresis of less than $10^{\circ}$ ). Such superhydrophobicity results from the high-aspect-ratio hydrophobic nanostructures of Teflon FEP, which can entrain air beneath the liquid droplet due to surface tension effects. Moreover, the results show that superhydrophobicity does not vary among the samples, indicating that the hot embossing process is reproducible with good uniformity over the sample area.

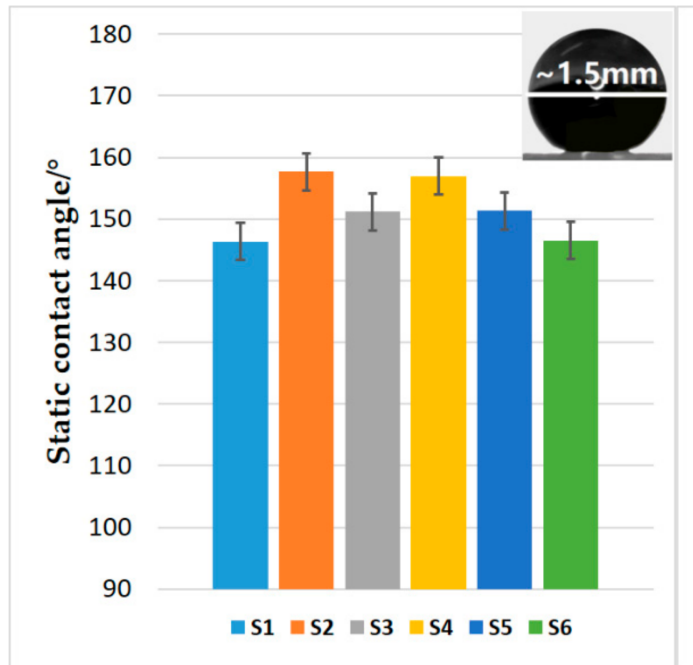

(a)

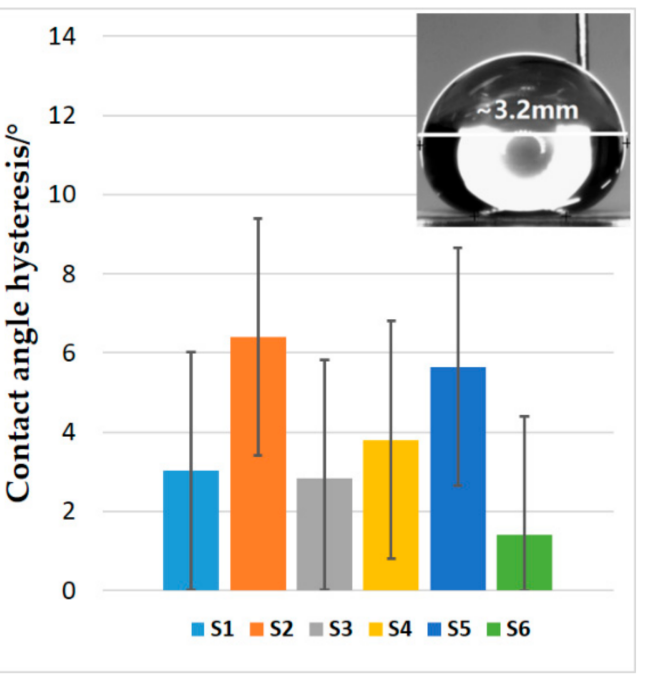

(b)

Figure 7. The apparent quasi-static contact angles (a), and contact angle hysteresis (b) of six different Teflon FEP surfaces with high-aspect-ratio nanowire structures made with the same AAO molds of SP-01. The inset in each figure shows an exemplary image of a sessile droplet of water used for the contact angle measurement.

\subsection{Underwater Superhydrophobicity of Nanowired Teflon FEP Surfaces in Turbulent Flow}

Such superhydrophobicity can be useful for many applications. Especially, the air retained on the surface can reduce the hydrodynamic skin friction due to the low viscosity of the air, as compared with that of water [55]. In such an underwater application, it is critical to retain the air for a relatively long operation time under high pressure and shear flow. For example, under a highly pressurized condition, water can fill the air cavities by the hydraulic force, and the air is also prone to diffusion and dissolution into water, thermodynamically following Henry's law [61], which significantly depends on the physical parameters (e.g., shape and dimension) of the surface structure. In addition to hydrodynamic pressure, turbulent-flow fluctuations can also cause the depletion of the air on the superhydrophobic surface [62]. Especially, the previous work [55] showed that significant loss of air on the superhydrophobic surface could happen due to the shearing effect in high Reynolds number turbulent flows, which would be further affected by the mechanical properties (e.g., pliability) of the surface structures. To examine 
and demonstrate the robustness of the high-aspect-ratio and flexible nanowire structures of Teflon in retaining the air under a hydrodynamically shearing condition, the nanowired FEP surface was tested in a turbulent flow, as shown in Figure 4. The estimated water pressure around the sample was less than 1 mbar [63] and the water was fully saturated with air so that the filling of water into the air cavities by the pressure or diffusion was negligible in our test condition. The underwater air-retentivity of the nanowired FEP surface, made using the AAO mold of SP-01 in a turbulent flow (water flow velocities of $\sim 1.2 \mathrm{~m} / \mathrm{s}$, Reynolds number of $\sim 6.7 \times 10^{4}$ ), is shown in Figure 8 . The coverage of air over the nanowired Teflon FEP surface before applying the turbulent flow, which can be identified by the silvery sheen reflected by the air layer, is shown in Figure 8a. For comparison, the coverage of air on the nanowired FEP surface after applying the turbulent flow for $6.5 \mathrm{~h}$ is shown in Figure $8 \mathrm{~b}$. It can be observed that there was no significant change in the air coverage even after turbulent flow was applied for $6.5 \mathrm{~h}$. This indicates the great air-retentivity of the nanowired FEP surface under a high shearing flow, which is important for the reliability and robustness of the superhydrophobicity of the nanowired FEP surface for real applications, such as hydrodynamic drag reduction [55].

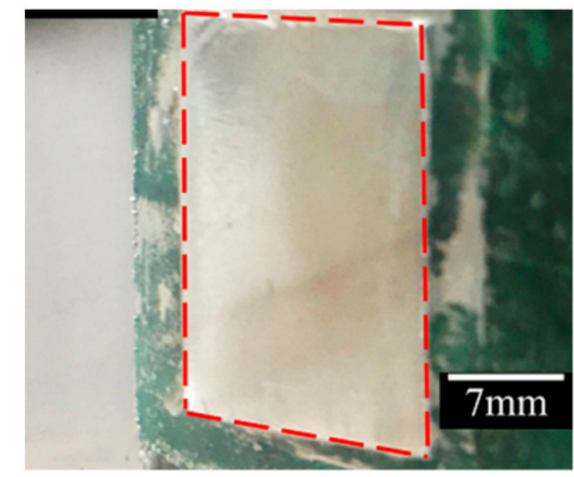

(a)

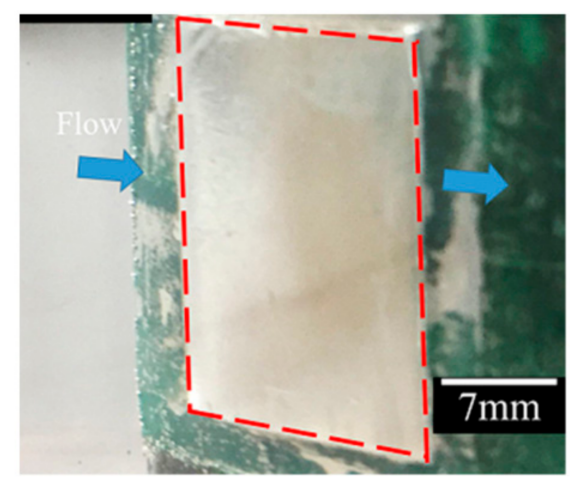

(b)

Figure 8. Measurement of underwater air-retentivity of the nanowired Teflon FEP superhydrophobic surface in a turbulent flow: (a) before flow; (b) after $6.5 \mathrm{~h}$ of turbulent flow, where the flow direction was tangential to the nanowired Teflon FEP surface, as indicated by the arrows in the image. In each image, the dashed lines (red in color) represent the boundary of the specimen, whose inner area is fully covered by an air layer.

\subsection{Hierarchical Micro/Nanostructures of Whole Teflon}

After the nanowire structures were formed by the first hot embossing step, microstructures were further fabricated on the nanostructured Teflon FEP via the second hot embossing step. The SEM image of the microhole structures of the whole Teflon, whose surfaces hierarchically feature the nanowire structures using the micropillar silicon mold (Figure 3a) for the second hot embossing process, is shown in Figure 9a. The SEM image of the micrograte structures, coupled with the nanowire structures using the micrograte silicon mold (Figure 3b), are shown in Figure 9b. The result shows that the non-compressed areas (no hard contact with the silicon mold) were covered with the nanowires, which were predefined in the first hot embossing step, and had no significant deformation or damage. In contrast, the nanowires in the compressed areas (hard contact with the silicon mold) were flattened down, but not melted down, since the temperature applied in the second hot embossing step $\left(100{ }^{\circ} \mathrm{C}\right)$ was much lower than the melting point of the Teflon FEP $\left(260^{\circ} \mathrm{C}\right)$. 


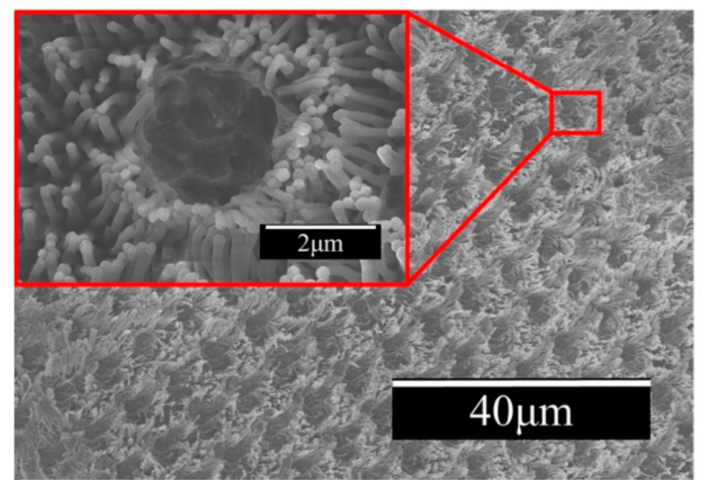

(a)

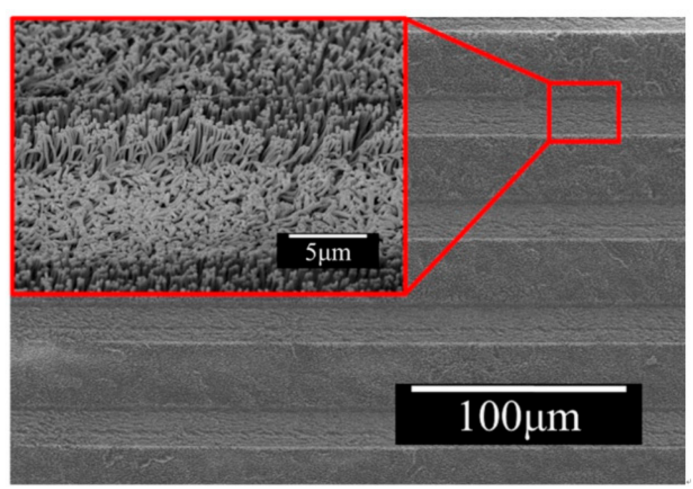

(b)

Figure 9. SEM images of the hierarchical micro/nanostructures of whole Teflon by two-step hot embossing processes. (a) Microholed surface featuring nanowire structures; (b) Micrograted surface featuring nanowire structures.

\section{Conclusions}

The results shown in this work demonstrate that a simple hot embossing process, using nanoporous AAO membranes, can realize the fabrication of high-aspect-ratio nanowire structures of whole Teflon. Key processing parameters, i.e., the molding temperature, heating time and aspect ratio of the nanopore structures of the AAO molds, have been investigated in order to achieve a high fidelity pattern transfer. In this work, nanowires formed with an AAO mold (with a molding temperature of $340^{\circ} \mathrm{C}$, which is greater than the melting temperature of the Teflon), whose aspect ratio is less than 10:1, give the best result in terms of yield and structure quality. In addition, as the heating time increases, the aspect ratio of nanowires rapidly increases. Thus, we can produce nanowires with different aspect ratios by controlling the heating time. The contact angle measurements and the underwater air-retentivity test in a turbulent flow show the strong superhydrophobicity of the nanowired Teflon FEP surface and the great robustness of superhydrophobicity. The repetition of the hot embossing process further allows us to achieve hierarchical patterning of the whole Teflon sheet for the production of dual-scale (micro and nano) structures. The second hot embossing step, in which the embossing temperature is lower than the melting point of the Teflon, retains the original nanowire structures predefined in the first hot embossing step with no significant deformation or damage, especially over the areas that are not compressed by the mold. The simple and scalable hot embossing techniques for the formation of high-aspect-ratio nanowires as well as hierarchical micro/nanostructures of whole Teflon, demonstrated in this study, will be of great significance for a wide range of applications, in which the unique physical and chemical properties of the Teflon material are critical, such as superhydrophobic surfaces, hydrodynamic drag reduction, anti-fouling, anti-corrosion, anti-icing, microfluidics systems, and sensors.

Author Contributions: Supervision, G.S. and C.-H.C.; Conceptualization, G.S.; Methodology, validation and investigation, J.L.; Data analysis, J.L., W.Y. and D.Z.; Writing, J.L., W.Y., D.Z., X.Z., C.-H.C. and G.S.

Funding: This work has been supported by the National Science Foundation of China (No. 51405245), the Key Program of Science Foundation Tianjin (No. 16JCZDJC30200), The National Natural Science Foundation of China (No. 61327802 and No. U1613200), and the National Science Foundation of the United States of America (Award Number 1462499).

Conflicts of Interest: The authors declare no conflict of interest.

\section{References}

1. Feng, L.; Li, S.; Li, Y.; Li, H.; Zhang, L.; Zhai, J.; Song, Y.; Liu, B.; Jiang, L.; Zhu, D. Super-hydrophobic surfaces: From natural to artificial. Adv. Mater. 2002, 14, 1857-1860. [CrossRef] 
2. Yilgor, I.; Bilgin, S.; Isik, M.; Yilgor, E. Facile preparation of superhydrophobic polymer surfaces. Polymer 2012, 53, 1180-1188. [CrossRef]

3. Roach, P.; Shirtcliffe, N.J.; Newton, M.I. Progress in superhydrophobic surface development. Soft Matter 2008, 4, 224-240. [CrossRef]

4. Hou, X.; Hu, Y.; Grinthal, A.; Khan, M.; Aizenberg, J. Liquid-based gating mechanism with tunable multiphase selectivity and antifouling behaviour. Nature 2015, 519, 70-73. [CrossRef] [PubMed]

5. Liu, Y.; Wang, X.; Fei, B.; Hu, H.; Lai, C.; Xin, J.H. Bioinspired, stimuli-responsive, multifunctional superhydrophobic surface with directional wetting, adhesion, and transport of water. Adv. Funct. Mater. 2015, 25, 5047-5056. [CrossRef]

6. Lu, Y.; Sathasivam, S.; Song, J.; Crick, C.R.; Carmalt, C.J.; Parkin, I.P. Robust self-cleaning surfaces that function when exposed to either air or oil. Science 2015, 347, 1132-1135. [CrossRef] [PubMed]

7. Lee, Y.; Park, S.H.; Kim, K.B.; Lee, J.K. Fabrication of hierarchical structures on a polymer surface to mimic natural superhydrophobic surfaces. Adv. Mater. 2007, 19, 2330-2335. [CrossRef]

8. Blossey, R. Self-cleaning surfaces-Virtual realities. Nat. Mater. 2003, 2, 301-306. [CrossRef] [PubMed]

9. Genzer, J.; Efimenko, K. Creating long-lived superhydrophobic polymer surfaces through mechanically assembled monolayers. Science 2000, 290, 2130-2133. [CrossRef] [PubMed]

10. Zhao, N.; Weng, L.; Zhang, X.; Xie, Q.; Zhang, X.; Xu, J. A lotus-leaf-like superhydrophobic surface prepared by solvent-induced crystallization. ChemPhysChem 2006, 7, 824-827. [CrossRef] [PubMed]

11. Zhang, J.; Lu, X.; Huang, W.; Han, Y. Reversible superhydrophobicity to superhydrophilicity transition by extending and unloading an elastic polyamide film. Macromol. Rapid Commun. 2005, 26, 477-480. [CrossRef]

12. Erbil, H.Y.; Demirel, A.L.; Avc1, Y.; Mert, O. Transformation of a simple plastic into a superhydrophobic surface. Science 2003, 299, 1377-1380. [CrossRef] [PubMed]

13. Jin, M.; Feng, X.; Xi, J.; Zhai, J.; Cho, K.; Feng, L.; Jiang, L. Super-hydrophobic PDMS surface with ultra-low adhesive force. Macromol. Rapid Commun. 2005, 26, 1805-1809. [CrossRef]

14. Guo, Z.; Zhou, F.; Hao, J.; Liu, W. Stable biomimetic super-hydrophobic engineering materials. J. Am. Chem. Soc. 2005, 127, 15670-15671. [CrossRef] [PubMed]

15. Qian, B.; Shen, Z. Fabrication of superhydrophobic surfaces by dislocation-selective chemical etching on aluminum, copper, and zinc substrates. Langmuir 2005, 21, 9007-9009. [CrossRef] [PubMed]

16. Northen, M.T.; Turner, K.L. Meso-scale adhesion testing of integrated micro- and nano-scale structures. Sens. Actuators A Phys. 2006, 130-131, 583-587. [CrossRef]

17. Hang, T.; Li, M.; Hu, A.; Mao, D. Super-hydrophobic nickel films with micro-nano hierarchical structure prepared by electrodeposition for appliance industry. In Proceedings of the International Conference on Electronic Packaging Technology and High Density Packaging, Beijing, China, 10-13 August 2009; pp. 684-686.

18. Xu, J.; Wang, K.; Zu, S.Z.; Han, B.H.; We, Z. Hierarchical nanocomposites of polyaniline nanowire arrays on graphene oxide sheets with synergistic effect for energy storage. ACS Nano 2010, 4, 5019-5026. [CrossRef] [PubMed]

19. Chen, J.; Zhu, G.; Yang, J.; Jing, Q.; Bai, P.; Yang, W.; Qi, X.; Su, Y.; Wang, Z.L. Personalized keystroke dynamics for self-powered human-machine interfacing. ACS Nano 2015, 9, 105-116. [CrossRef] [PubMed]

20. Chu, P. A very dennison micro-nano replication capabilities for MEMS and microfluidics. In Proceedings of the International Conference on MEMS, Nano and Smart Systems, Banff, AB, Canada, 24-27 July 2005; pp. 27-29.

21. Huang, C.F.; Lin, Y.; Shen, Y.K.; Fan, Y.M. Optimal processing for hydrophobic nanopillar polymer surfaces using nanoporous alumina template. Adv. Mater. Res. 2014, 646, 84-89. [CrossRef]

22. Tawfick, S.; Volder, M.D.; Copic, D.; Park, S.J.; Oliver, C.R.; Polsen, E.S.; Roberts, M.J.; Hart, A.J. Engineering of micro- and nanostructured surfaces with anisotropic geometries and properties. Adv. Mater. 2012, 24, 1628-1674. [CrossRef] [PubMed]

23. Becker, H.; Heim, U. Hot embossing as a method for the fabrication of polymer high aspect ratio structures. Sens. Actuators A Phys. 2000, 83, 130-135. [CrossRef]

24. Konstantinou, D.; Shirazi, A.; Sadri, A.; Young, E.W.K. Combined hot embossing and milling for medium volume production of thermoplastic microfluidic devices. Sens. Actuators B Chem. 2016, 234, 209-221. [CrossRef]

25. Pethrick, R.A. Polymer Physics; Rubinstein, M., Colby, R.H., Eds.; Oxford University Press: Oxford, UK, 2003; ISBN 019852059X. pp. 440. [CrossRef] 
26. Carlson, D.P.; Schmiegel, W. Fluoropolymers, Organic. In Ullmann's Encyclopedia of Industrial Chemistry; Wiley-VCH Verlag GmbH \& Co. KGaA: Weinheim, Germany, 2000.

27. Koponen, H.K.; Saarikoski, I.; Korhonen, T.; Pääkkö, M.; Kuisma, R.; Pakkanen, T.T.; Suvanto, M.; Pakkanen, T.A. Modification of cycloolefin copolymer and poly (vinyl chloride) surfaces by superimposition of nano- and microstructures. Appl. Surf. Sci. 2007, 253, 5208-5213. [CrossRef]

28. Wu, J.; Zan, X.; Li, S.; Liu, Y.; Cui, C.; Zou, B.; Zhang, W.; Xu, H.; Duan, H.; Tian, D.; et al. In situ synthesis of large-area single sub-10 nm nanoparticle arrays by polymer pen lithography. Nanoscale 2014, 6, 749-752. [CrossRef] [PubMed]

29. Madaria, A.R.; Yao, M.; Chi, C.Y.; Huang, N.F.; Lin, C.X.; Li, R.J.; Povinelli, M.L.; Dapkus, P.D.; Zhou, C. Toward optimized light utilization in nanowire arrays using scalable nanosphere lithography and selected area growth. Nano Lett. 2012, 12, 2839-2845. [CrossRef] [PubMed]

30. Fujita, J.; Ohnishi, Y.; Ochiai, Y.; Matsui, S. Ultrahigh resolution of calixarene negative resist in electron beam lithography. Appl. Phys. Lett. 1996, 68, 1297-1299. [CrossRef]

31. Du, K.; Wathuthanthri, I.; Liu, Y.; Kang, Y.T.; Choi, C.-H. Fabrication of polymer nanowires via maskless $\mathrm{O}_{2}$ plasma etching. Nanotechnology 2014, 25, 165301. [CrossRef] [PubMed]

32. Canham, L.T. Silicon quantum wire array fabrication by electrochemical and chemical dissolution of wafers. Appl. Phys. Lett. 1990, 57, 1046-1048. [CrossRef]

33. Lee, W.; Jin, M.K.; Yoo, W.C.; Lee, J.K. Nanostructuring of a polymeric substrate with well-defined nanometer-scale topography and tailored surface wettability. Langmuir 2004, 20, 7665-7669. [CrossRef] [PubMed]

34. Guo, C.; Feng, L.; Zhai, J.; Wang, G.; Song, Y.; Jiang, L.; Zhu, D. Large-area fabrication of a nanostructure-induced hydrophobic surface from a hydrophilic polymer. ChemPhysChem 2004, 5, 750-753. [CrossRef] [PubMed]

35. Feng, X.J.; Jiang, L. Design and creation of superwetting/antiwetting surfaces. Adv. Mater. 2006, 18, 3063-3078. [CrossRef]

36. Wu, J.T.; Chang, W.Y.; Yang, S.Y. Fabrication of a nano/micro hybrid lens using gas-assisted hot embossing with an anodic aluminum oxide (AAO) template. J. Micromech. Microeng. 2010, 20, 669-672. [CrossRef]

37. Gates, B.D.; Xu, Q.; Stewart, M.; Ryan, D.; Willson, C.G.; Whitesides, G.M. New approaches to nanofabrication: Molding, printing, and other techniques. Chem. Rev. 2005, 36, 1171-1196. [CrossRef] [PubMed]

38. Guo, L.J. Recent progress in nanoimprint technology and its applications. J. Phys. D Appl. Phys. 2004, 37, 123-141. [CrossRef]

39. Dirckx, M.E.; Hardt, D.E. Analysis and characterization of demolding of hot embossed polymer microstructures. J. Micromech. Microeng. 2011, 21, 085024. [CrossRef]

40. Schaper, C.D. Water-soluble polymer templates for high-resolution pattern formation and materials transfer printing. J. Microlithogr. Microfabr. Microsyst. 2004, 3, 174-185. [CrossRef]

41. Telecka, A.; Murthy, S.; Sun, L.; Pranov, H.; Taboryski, R.J. Superhydrophobic properties of nanotextured polypropylene foils fabricated by roll-to-roll extrusion coating. ACS Macro Lett. 2016, 5, 1034-1038. [CrossRef]

42. Xu, M.; Sun, G.; Kim, C.J. Infinite lifetime of underwater superhydrophobic states. Phys. Rev. Lett. 2014, 113, 136103. [CrossRef] [PubMed]

43. Ren, K.; Dai, W.; Zhou, J.; Su, J.; Wu, H. Whole-teflon microfluidic chips. Proc. Natl. Acad. Sci. USA 2011, 108, 8162-8166. [CrossRef] [PubMed]

44. Yang, Y.; Huang, X.; Zhang, X.; Jiang, F.; Zhang, X.; Wang, Y. Supercritical fluid driven polymer phase separation for microlens with tunable dimension and curvature. ACS Appl. Mater. Interfaces 2016, 8, 8849-8858. [CrossRef] [PubMed]

45. Lee, W.; Ji, R.; Gösele, U.; Nielsch, K. Fast fabrication of long-range ordered porous alumina membranes by hard anodization. Nat. Mater. 2006, 5, 741-747. [CrossRef] [PubMed]

46. Lee, W.; Schwirn, K.; Steinhart, M.; Pippel, E.; Scholz, R.; Gösele, U. Structural engineering of nanoporous anodic aluminum oxide by pulse anodization of aluminum. Nat. Nanotechnol. 2008, 3, 234-239. [CrossRef] [PubMed]

47. Jeong, C.; Choi, C.H. Single-step direct fabrication of pillar-on-pore hybrid nanostructures in anodizing aluminum for superior superhydrophobic efficiency. ACS Appl. Mater. Interfaces 2012, 4, 842-848. [CrossRef] [PubMed] 
48. Saha, B.; Toh, W.Q.; Liu, E.; Tor, S.B.; Hardt, D.E.; Lee, J. A review on the importance of surface coating of micro/nano-mold in micro/nano-molding processes. J. Micromech. Microeng. 2016, 26, 013002. [CrossRef]

49. Zhao, T.; Jiang, L. Contact angle measurement of natural materials. Colloids Surf. B Biointerfaces 2017, 161, 324-330. [CrossRef] [PubMed]

50. Liu, T.L.; Chen, Z.; Kim, C.-J. A dynamic cassie-baxter model. Soft Matter 2015, 11, 1589-1596. [CrossRef] [PubMed]

51. Koch, K.; Barthlott, W. Superhydrophobic and superhydrophilic plant surfaces: An inspiration for biomimetic materials. Philos. Trans. R. Soc. A Math. Phys. Eng. Sci. 2009, 367, 1487-1509. [CrossRef] [PubMed]

52. Lydéric, B.; Eric, L. A smooth future? Nat. Mater. 2011, 10, 334-337.

53. Lee, C.; Choi, C.-H.; Kim, C.-J. Superhydrophobic drag reduction in laminar flows: A critical review. Exp. Fluids 2016, 57, 176. [CrossRef]

54. Daniello, R.J.; Waterhouse, N.E.; Rothstein, J.P. Drag reduction in turbulent flows over superhydrophobic surfaces. Phys. Fluids 2009, 21, 085103. [CrossRef]

55. Aljallis, E.; Sarshar, M.A.; Datla, R.; Sikka, V.; Jones, A.; Choi, C.-H. Experimental study of skin friction drag reduction on superhydrophobic flat plates in high Reynolds number boundary layer flow. Phys. Fluids 2013, 25, 351-412. [CrossRef]

56. Hizal, F.; Rungraeng, N.; Lee, J.; Jun, S.; Busscher, H.J.; van der Mei, H.C.; Choi, C.-H. Nanoengineered superhydrophobic surfaces of aluminum with extremely low bacterial adhesivity. ACS Appl. Mater. Interfaces 2017, 9, 12118-12129. [CrossRef] [PubMed]

57. Jeong, C.; Lee, J.; Sheppard, K.; Choi, C.-H. Air-impregnated nanoporous anodic aluminum oxide layers for enhancing the corrosion resistance of aluminum. Langmuir 2015, 31, 11040-11050. [CrossRef] [PubMed]

58. Sarshar, M.A.; Swarctz, C.; Hunter, S.; Simpson, J.; Choi, C.-H. Effects of contact angle hysteresis on ice adhesion and growth on superhydrophobic surfaces under dynamic flow conditions. Colloid Polym. Sci. 2013, 291, 427-435. [CrossRef]

59. Sommerfeld, A. A contribution to hydrodynamic explanation of turbulent fluid motions. Int. Congr. Math. 1908, 3, 116-124.

60. Mchale, G.; Newton, M.I.; Shirtcliffe, N.J. Immersed superhydrophobic surfaces: Gas exchange, slip and drag reduction properties. Soft Matter 2010, 6, 714-719. [CrossRef]

61. Søgaard, E.; Andersen, N.K.; Smistrup, K.; Larsen, S.T.; Sun, L.; Taboryski, R. Study of transitions between wetting states on microcavity arrays by optical transmission microscopy. Langmuir 2014, 30, 12960-12968. [CrossRef] [PubMed]

62. Rosenberg, B.J.; Van Buren, T.; Fu, M.K.; Smits, A.J. Turbulent drag reduction over air- and liquid-impregnated surfaces. Phys. Fluids 2016, 28, 015103. [CrossRef]

63. More, A.A. Analytical solutions for the Colebrook and White equation and for pressure drop in ideal gas flow in pipes. Chem. Eng. Sci. 2006, 61, 5515-5519. [CrossRef] 